Supplemental Information

\title{
Double-Shell Lignin Nanocapsules Are a Stable Vehicle for Fungicide Encapsulation and Release
}

Raisa Carmen Andeme Ela†, Momoko Tajirił, Nick K. Newberrył, Patricia A. Heidenћ, Rebecca G. Ong†

$†$ Department of Chemical Engineering, Michigan Technological University, 1400 Townsend Dr, Houghton, MI 49931.

\$Department of Chemistry, Michigan Technological University, 1400 Townsend Dr, Houghton, MI 49931.

Corresponding author: randemee@mtu.edu; +1 (906-395-7091).

Notes: The authors declare no competing financial interest.

Number of Pages: 5

Number of Tables: 3

Number of Figures: 2

Section I: Experimental

Section II: Results and Discussion 


\section{Section I: Experimental}

\section{Kraft lignin Characterization}

Oven-dried kraft lignin was acetylated by reacting a $100 \mathrm{mg}$ sample with $5 \mathrm{~mL}$ of a pyridine/acetic anhydride solution $(1: 1, \mathrm{v} / \mathrm{v})$ for 18 hours. The reaction was quenched with a 50\% aqueous methanol solution, and the pellet washed sequentially with $99.5 \%$ methanol, distilled water and 95\% ethanol [1]. The relative molecular weight of the acetylated kraft lignin was determined from size exclusion chromatography (Malvern OMNISEC), with tetrahydrofuran as the mobile phase, and the analysis was performed by polystyrene standards with an exclusion limit of $400 \mathrm{kDa}$.

The hydroxyl content was analyzed via ${ }^{31} \mathrm{P}-\mathrm{NMR}$ (Unity Inova, Varian, $400 \mathrm{mHz}$ ) at $25^{\circ} \mathrm{C}$. The sample was prepared by dissolving $\sim 40 \mathrm{mg}$ of oven-dried lignin in $500 \mu \mathrm{l}$ of an anhydrous pyridine/deuterated chloroform solution (1.6:1, $\mathrm{v} / \mathrm{v}$ ). To this, $100 \mu \mathrm{l}$ of cyclohexanol, $50 \mu \mathrm{l}$ of chromium (III) acetylacetone, and $100 \mu \mathrm{l}$ of 2-chloro-4,4,5,5tetramethyl-1,3,2-dioxaphospholane were added. The reaction proceeded for 25 minutes, and $600 \mu l$ of the mixture was transferred to an NMR tube for analysis with a relaxation delay of $5 \mathrm{~s}$ and though 512 scans. Cyclohexanol was taken as the internal standard and the different hydroxyl group contents were calculated based on the ratio of the integrated area peaks. The following spectral regions were considered: aliphatic hydroxyls (149.1-145.4 ppm), cyclohexanol (145.3-144.9 ppm), syringyl phenolic hydroxyls (143.3-142.0 ppm), guaiacyl phenolic hydroxyls (140.5-138.6 ppm), p-hydroxyphenyl hydroxyls (138.5-137.3 ppm), and carboxyl hydroxyls (135.9-134 ppm) [2].

The atomic concentration of carbon and oxygen was analyzed by X-ray photoelectron spectrometer (PHI 5800) using a magnesium $(\mathrm{Mg})$ beam. Analysis was performed using the XPS Casa software.

Sodium content was measured by X-ray fluorescence spectrometer (Xenemetrix EX-6600 EDS), and analyzed from calibration standards.

The residual sugars in kraft lignin were hydrolyzed [3], and the hydrolysate analyzed by high performance liquid chromatography (HPLC) (1100 series, RID and DAD, Agilent Technologies) in a HPX-87 P-Column (300 x 7.8 mm) with ultra-filtered water as the mobile phase. The analysis was performed by calibration standards for the sugar moieties, glucose, xylose, mannose, arabinose, and galactose.

\section{Red fluorescence label addition to propiconazole}

In a typical experiment, $10 \mathrm{mg}$ of propiconazole was dissolved in $100 \mathrm{~mL}$ ultra-filtered water. To it, $5 \mathrm{mg}$ of ammonium tetrachlorocuprate (II) dihydrate, $1 \mathrm{mg}$ of $95 \% \mathrm{Cy} 5$-alkyne, and $0.1 \mathrm{~mL}$ of a sodium acetylide suspension in xylene were added. The reaction was conducted at ambient conditions. The reaction pathway was developed based on an idea obtained from Lumiprobe life sciences solutions' website [4]. 


\section{Section II: Results and Discussion}

Table S1. Evidence of removal of surfactant using elemental concentrations of sulfur and sodium determined by EDS.

\begin{tabular}{|l|l|l|}
\hline \multirow{2}{*}{} & \multicolumn{2}{|l|}{ Atomic fraction (\%) } \\
\cline { 2 - 3 } & $\mathrm{S}$ & $\mathrm{Na}$ \\
\hline Kraft lignin & $0.5 \pm 0.2$ & $1.8 \pm 0.7$ \\
\hline Single shell + SDS & $1.1 \pm 0.4$ & $0.2 \pm 0.1$ \\
\hline Single shell & $0.2 \pm 0.1$ & $0.2 \pm 0.1$ \\
\hline Double shell + SDS & $1.3 \pm 0.5$ & $0.8 \pm 0.3$ \\
\hline Double shell & $0.5 \pm 0.1$ & $0.1 \pm 0.0$ \\
\hline
\end{tabular}

Table S2. Concentration changes of the elemental composition of nanocapsules at different stages of formation. Increased nitrogen concentration correlates to increased propiconazole encapsulation.

\begin{tabular}{|l|l|l|l|l|l|}
\hline & \multicolumn{4}{|l}{ Atomic fraction (\%) } \\
\cline { 2 - 6 } & $\mathrm{C}$ & $\mathrm{O}$ & $\mathrm{N}$ & $\mathrm{S}$ & $\mathrm{Na}$ \\
\hline Kraft lignin & $93.1 \pm 2.2$ & $4.1 \pm 1.4$ & 0 & $0.5 \pm 0.2$ & $1.8 \pm 0.7$ \\
\hline Single shell & $94.1 \pm 2.0$ & $4.5 \pm 0.1$ & 0 & $0.2 \pm 0.1$ & $0.4 \pm 0.2$ \\
\hline Double shell & $93.3 \pm 0.4$ & $5.5 \pm 1.1$ & $0.7 \pm 0.2$ & $0.5 \pm 0.1$ & $0.1 \pm 0.0$ \\
\hline $\begin{array}{l}\text { Double shell }+ \\
\text { propiconazole }\end{array}$ & $91.2 \pm 2.7$ & $5.6 \pm 1.1$ & $2.5 \pm 0.5$ & $0.3 \pm 0.1$ & $0.4 \pm 0.1$ \\
\hline
\end{tabular}

Table S3. Tukey pairwise comparisons of hydrodynamic size of the nanocapsule as a function of $\mathrm{pH}$. Analysis performed in Minitab.

\begin{tabular}{|l|l|l|l|}
\hline Solution $\mathrm{pH}$ & $\begin{array}{l}\text { Average } \\
\text { hydrodynamic size } \\
(\mathrm{nm})\end{array}$ & $\begin{array}{l}\text { Standard deviation } \\
(\mathrm{nm})\end{array}$ & Grouping \\
\hline 2 & 1139.5 & 12.0 & $\mathrm{~A}$ \\
\hline 4 & 468.5 & 74.1 & $\mathrm{~B}$ \\
\hline 7 & 241.8 & 33.3 & $\mathrm{~B}$ \\
\hline 8 & 1711.0 & 140.0 & $\mathrm{C}$ \\
\hline 10 & 2401.5 & 132.2 & $\mathrm{D}$ \\
\hline 12 & 2725.2 & $\mathrm{D}$ \\
\hline S Samples that do not share a letter are statistically different. \\
\hline
\end{tabular}




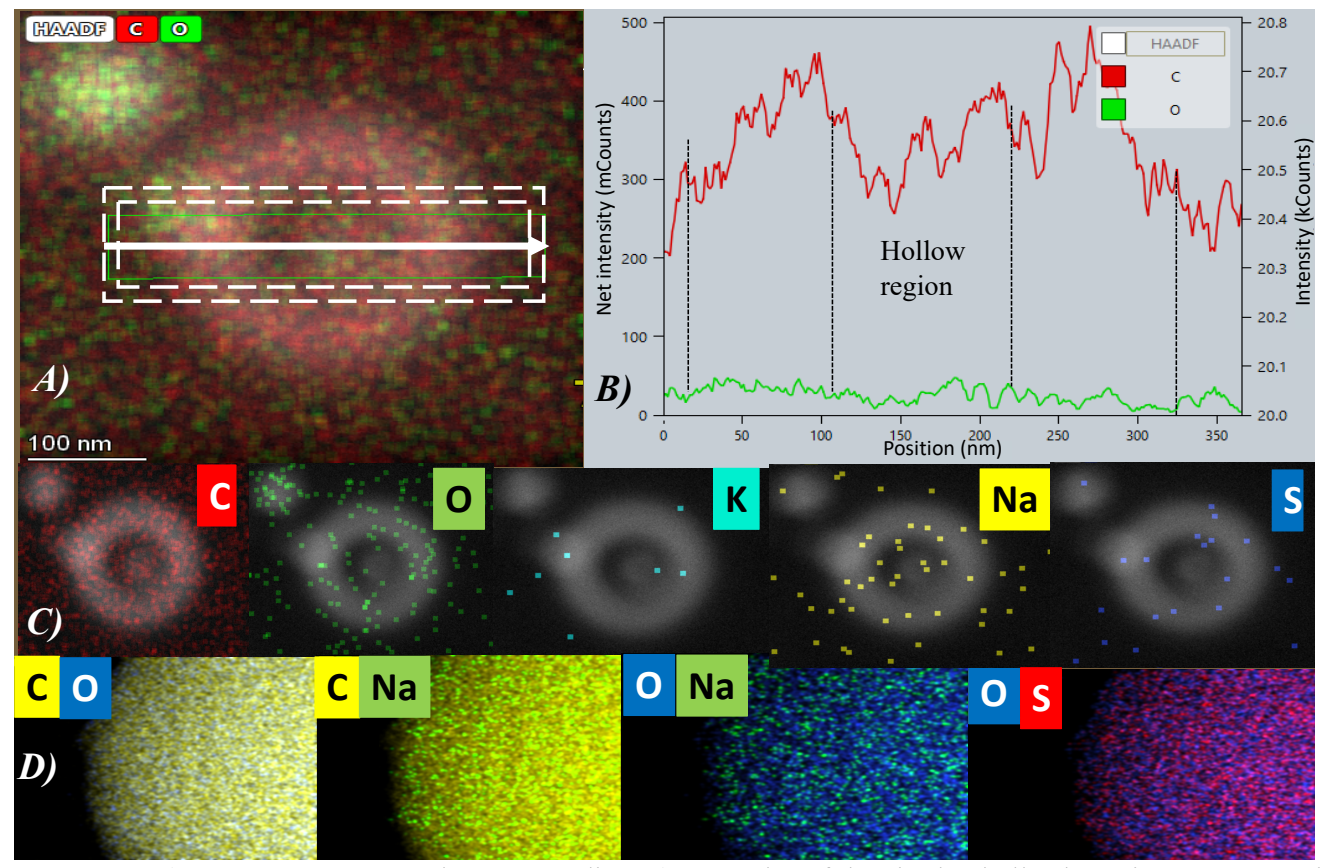

Figure S1. A) HAADF spectra and corresponding B) EDS plot of the single-shell. The units represent milli Counts (mCounts) and kilo Counts (kCounts). The black dashed lines show transitions from one nanoparticle domain to another. C) Elemental distribution on the surface of the single-shell. D) Elemental distribution on the surface of the double-shell.

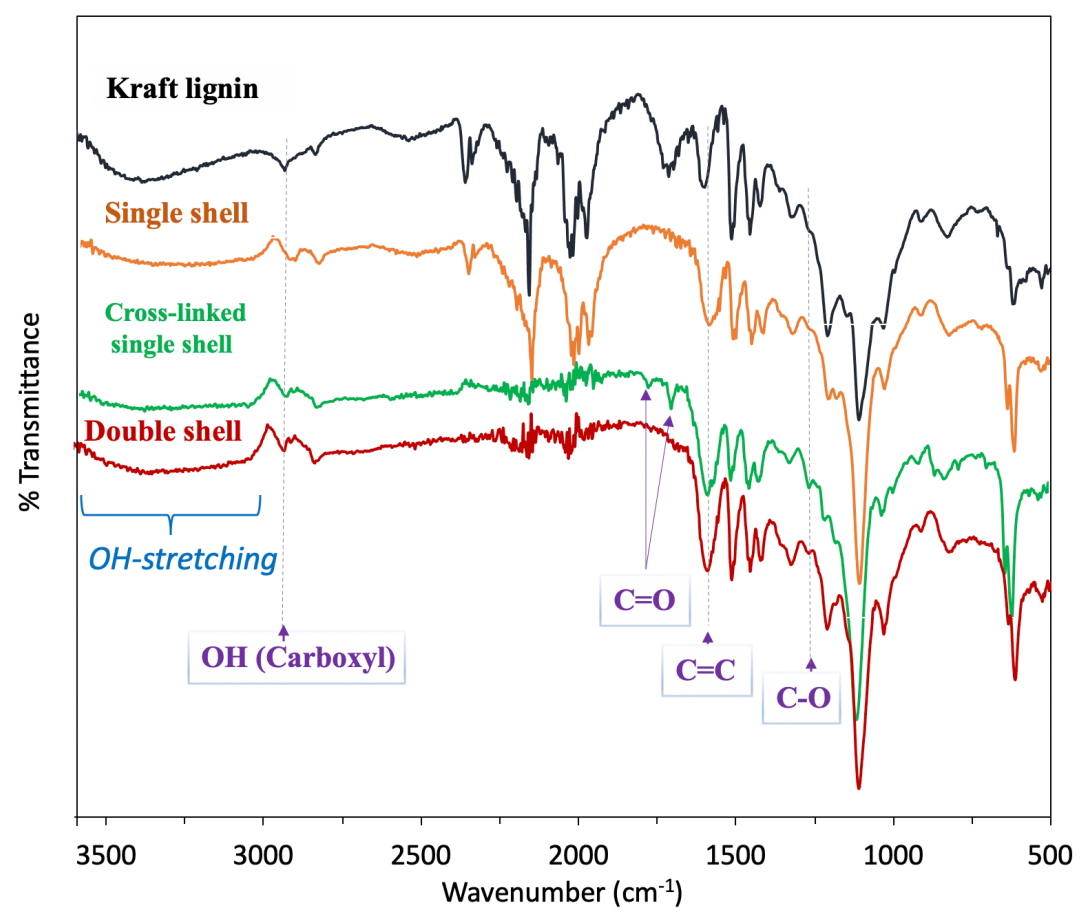

Figure S2. FTIR spectra of kraft lignin, non-crosslinked single shell, cross-linked single shell, and cross-linked double-shell nanocapsules. The spectra have been stacked vertically for clarity. 


\section{References:}

[1] Zoia, L.; Salanti, A.; Frigerio, P.; Orlandi, M. Exploring allylation and claisen rearrangement as a novel chemical modification of lignin. Bioresources 2014, 9 (4), 6540-6561.

[2] Argyropoulos, D. S. Quantitative 31p-nmr analysis of lignins, a mew tool for the lignin chemist. J. Wood Chem. Technol. 1994, 14 (1), 45-63, DOI 10.1080/02773819408003085.

[3] Sluiter, A. H. B.; Ruiz, R.; Scarlata, C.; Sluiter, J.; Templeton, D.; Crocker, D. Determination of structural carbohydrate and lignin in biomass. National Renewable Energy Laboratory 2019.

[4] Lumiprobe Life Sciences Slolutions. Cyanine5 alkyne. https://www.lumiprobe.com/p/cy5alkyne?gclid=EAlalQobChMI8dX7tYDT6wIVRr7ACh251gpFEAAYASAAEgL7LvD_BwE (Accessed 2020). 